\title{
General Discussion to Papers of Professor Lacert and co-workers and Dr Rossier et al.
}

\author{
Chairman: Professor A. Rossier.
}

The Discussion is opened. Sir Ludwig?

Sir LudWIG GutTMANN (G.B.). I'd like to make comments to the two papers and first to the paper of the many French colleagues. Our common language in this international society is English and I was disappointed that the charts which have been shown here were in French. This must lead to misunderstanding. Secondly the chart given of sensibility is incorrect as the denervation of $\mathrm{T}_{\mathrm{I}}$ is not at the armpits as shown but on the innerside of the forearm. I feel sensibility charts must be in accordance with the generally accepted anatomical distribution of spinal segments or spinal roots. With regard to the whole content of this paper, I really do not understand the rationality why it has been given as members of this society are really familiar with the techniques of examination of spinal cord injuries as far as motor function, sensory function, bladder and autonomic functions are concerned. I am afraid, speaking as editor of our journal, unless your charts and your paper are put into proper English it cannot be accepted for Paraplegia. Secondly to Alain's paper. Although I have in my own book reported that under certain circumstances caused by the patient's position the extensor reflex may appear earlier than the flexor reflex this paper cannot change the facts already shown in Sherrington's classic findings and mine and many other neuro-physiologists, that the flexor response is the primary response following spinal cord transection. Sherrington was puzzled that in one of his cats the extensor response preceded the flexor and he mentioned that perhaps the position of the animal after the transection of the cord may have been the reason. Now that was one of the points in my own research in the spinal man to examine carefully the positioning of the patient immediately after injury. Although I confirmed Sherrington's views that the primary return of reflex function is the flexor response there is no doubt whatsoever, that in man the positioning after complete lesion of the spinal cord in extension and adduction of the legs may alter the preponderance of the flexor synergy. I would like to ask Rossier what he means with phasic response, but I would not accept that the extensor response is the primary reflex response. Perhaps you would be good enough to explain what is phasic response.

Prof. A. Rossier (U.S.A.). Phasic stretch response.

SiR LuDWig GutTMANN. Plantar stimulation is a deep reflex, the deepest reflex of all. Tapping the knee produces another reflex but is certainly not as profound a stimulation as the plantar stimulation.

Prof. A. Rossier. The point which we made was to compare the phasic stretch reflex which is a D.T.R. by exciting skin areas response to the pin prick. There is a difference and this causes the flexor response, flexor response not extensor. What we wanted is to show that by exciting of the skin in some patients there is a migration of the excitatory skin areas responses from the foot to the thigh as time passes by.

SIR LUDWIG GutTMANN. Now you say the right word 'in some patients' and I agree with that, but you made this quite dogmatic that this is a primary response in all cases and that is wrong.

Prof. Rossier. It was only 12 cases amongst ioo cases. It could be different but it was surprising that all these cases matched these results except two out of 12 .

SIR LUdWIG GutTManN. That is quite correct, in some cases I agree, but this is contrary to what you showed us in the slides.

DR G. S. BRINDLEY (G.B.). It's traditional in this country for anatomists and physiologists to define the sympathetic and parasympathetic systems as efferent systems and 
therefore the sensation, at any rate by conventions in this country, is neither parasympathetic nor sympathetic. I think this is absolutely clear, but whether it is different in other countries, I've not heard it so. (Laughter). But, I can of course ask, do these fibres travel with sympathetic or parasympathetic pathways even if one denies that they belong to these. Surely the answer there is also neither. They do not travel in the sympathetic chain, they do not travel with any recognised system of parasympathetic nerves either.

DR P. Dollfus (France). We see acute cases in coma coming in half an hour after the accident. First of all of the I22I cases the Franco-Swiss group has examined there are 6.7 per cent of people with spinal cord lesions with a coma and approximately 30 per cent with a head injury. Now as coma is concerned I would insist that such people should not be transported flat, but as Sir Ludwig mentioned a long time ago on the side.

Mr P. Harris (G.B.). Firstly with regard to sensory dermatomes, if we look at the various books of various authorities on the sensory dermatomes, we will see that there are about five varieties. I think it would be wonderful if we as a Society could possibly fix on one standard sensory dermatome pattern, I mean about the five that exist.

PROFESSOR ROSSIER. In answer to the dermatome problems I have looked personally at these rather closely and you are certainly correct, one can make some mixture from Keegan and Bing and the other ones and you will see that Foerster's, I think you will agree with me Sir Ludwig, is probably the closest to the truth, but none is absolutely correct. There is not one single which is exactly what we see when we see patient after patient. I speak of complete traumatic lesions. This is one point. Regarding priapus I don't know if anyone has any comment to do.

SIR LUDWIg GUTTMANN. In answer to Rossier, what is generally agreed by all investigators is that $T_{I}$ innervates the inner side of the forearm while $T_{3}$ innervates the armpit.

DR P. Dollfus (France). In our examination we do the clitoris-anal reflex but I have not observed any priapism of the clitoris. 